\title{
ERRATUM
}

\section{Design, construction and utilization of a university plasma laboratory - ERRATUM}

\author{
W. Gekelman, P. Pribyl, Z. Lucky, S. W. Tang, J. Han and Y. Qian \\ doi:10.1017/S002237782000063X, Published by Cambridge University Press, \\ 30 June 2020
}

The original version of this article was published with an editor's name misspelled in the acknowledgements. The correct acknowledgement should read as below.

Editor Hartmut Zohm thanks the referees for their advice in evaluating this article.

\section{REFERENCE}

Gekelman, W., Pribyl, P., Lucky, Z., Tang, S., Han, J. \& Qian, Y. 2020 Design, construction and utilization of a university plasma laboratory. J. Plasma Phys. 86 (3), 925860301. doi:10.1017/S002237782000063X 